\title{
Mercado, exploración y colonización. Las raíces epistemológicas de los saberes utilitarios de la Geografía Moderna
}

\section{Market, exploration and colonization. The epistemological roots of the utilitarian knowledge of modern Geography}

\author{
Héctor Ignacio Martínez-Álvarez ${ }^{1}$ \\ Universidad Nacional Autónoma de México, México
}

\begin{abstract}
Resumen
Este artículo busca indagar en los principales elementos históricos, teóricos y políticos que marcaron el origen de la llamada Geografía moderna desde la exploración filosófica, epistemológica y metodológica que desarrolló la ciencia moderna y su utilidad pragmática y utilitarista en el proceso de formación del mercado mundial capitalista, en particular en el proceso de colonización. A diferencia de trabajos que se han escrito sobre el tema, aquí se enfatiza en el papel legitimador que tuvieron los conocimientos, saberes y prácticas geográficas para la transición de la sociedad feudal a la capitalista, en específico el ascenso y la consolidación de la burguesía.
\end{abstract}

Palabras clave: Geografía moderna, colonización, epistemología y ciencia

\begin{abstract}
This article seeks to investigate the main historical, theoretical and political elements that marked the origin of the so-called Modern Geography from the philosophical, epistemological and methodological exploration that modern science advanced and its pragmatic and utilitarian usefulness in the process of shaping the capitalist world market, particularly in the process of colonization. Unlike previously written works on the subject matter, the present exposition emphasizes the legitimating role that knowledge and geographical practices had upon the transition from feudal to capitalist society, specifically the rise and consolidation of the bourgeoisie.
\end{abstract}

Keywords: Modern geography; Colonization; Epistemology and science

1 Licenciado y Maestro en Geografía por la Universidad Nacional Autónoma de México, actualmente estudiante de Doctorado en Geografía por la misma institución. Correo electrónico: hectorignacioma@gmail.com 


\section{Introducción}

\section{El origen de los conocimientos geográficos}

Como lo señala Richar Peet (2012), la Geografía moderna tal cual hoy se conoce, emergió como parte de una interpretación $<<$ científica $>>$ del mundo en contraste con las anteriores formas religiosas de entendimiento. Este camino se inició con la gran crisis general del orden feudal en Europa de los siglos XIV y XV que culminó más tarde con la violenta transición al modo de producción capitalista que implicó, entre otros aspectos, el debilitamiento de las concepciones teológicas medievales y el surgimiento de nuevas formas racionales de pensamiento, que manifestaban los intereses y el avance de la economía monetaria capitalista. El Renacimiento será la expresión de esta nueva forma de ver el mundo y al ser humano por parte de la naciente burguesía ${ }^{2}$. Durante el siglo XVI, las creencias eclesiásticas, las doctrinas cristianas y las ideas religiosas que reinaron durante la Edad Media, las cuales dejaron de lado el legado filosófico, cultural y científico desarrollado por la sociedad esclavista grecorromana durante el periodo Antiguo, fueron cediendo terreno a medida que el debilitamiento feudal se agudizó. Finalmente, con las álgidas rebeliones sociales de la época, la instauración de un poder centralizado y la expansión progresiva del capitalismo comienzan a florecer modernas y remozadas actitudes científicas que se harán cargo de explicar las bases y las causas de los complejos problemas que acarrea el advenimiento de la sociedad burguesa, principalmente el carácter irreconciliable de las contradicciones y la lucha de clases que suscita su desarrollo, el manejo eficiente de los negocios de los nuevos dueños del mundo y la necesidad de satisfacer la demanda creciente de producción.

Esto dio lugar a un temprano interés por el resurgimiento científico al exponer y tratar los nuevos asuntos que arrastraba el nacimiento de la economía y la política burguesa. Friedrich Engels y Karl Marx lo señalarían de la siguiente manera:

Dondequiera que ha conquistado el poder, la burguesía ha destruido las relaciones feudales, patriarcales, idílicas. Las densas ligaduras feudales

2 Para F. Engels (2006, p. 50), todo el periodo del Renacimiento, desde mediados del siglo XV, fue en esencia un producto de la naciente burguesía, y lo mismo cabe decir de la filosofía, desde entonces renaciente; su contenido no era, en sustancia, más que la expresión filosófica de las ideas correspondientes al proceso de desarrollo de la pequeña y mediana burguesía hacia la gran burguesía. 
que ataban al hombre a sus "superiores naturales" las han desgarrado sin piedad para no dejar subsistir otro vínculo entre los hombres que el frío interés, el cruel "pago al contado". Ha ahogado el sagrado éxtasis del fervor religioso, el entusiasmo caballeroso y el sentimentalismo del pequeño burgués en las aguas heladas del calculo egoista. Ha hecho de la dignidad personal un simple valor de cambio. Ha sustituido las numerosas libertades escrituradas y adquiridas por la única y desalmada libertad del comercio. En una palabra, en lugar de la explotación velada por ilusiones religiosas y políticas, ha establecido una explotación abierta, descarada, directa y brutal.( Engels y Marx, 2015, p. 119 [Cursiva añadida])

Frente a este hecho, se formularan nuevas ideas, definiciones y prácticas sobre la búsqueda de un conocimiento que transmitiera los sentidos e intereses de la temprana sociedad capitalista. Como diría Sergio Bagú (1980), no se trató de que el principio divino y los entes metafísicos hayan quedado expresamente desterrados del pensamiento científico, sino que, aunque se les mencione, su conexión con los fenómenos naturales y sociales aparece demasiado lejana, mientras que el filósofo y el investigador descubren a partir de ahora en los procesos un grado mucho mayor de complejidad e integración, que comienza a explicar mediante leyes y tendencias que son lógicamente válidas sin ninguna apelación a una instancia superior. Se inaugura definitivamente una nueva actitud científica o mejor dicho se lleva a cabo una revolución científica: cuyo resultado fue la formación de la ciencia moderna la cual desarrolló un conjunto de saberes prácticos frente a las concepciones filosóficas y teológicas. La esencia de esta forma de conocimiento será su método que se distingue en la medida que la observación, la experimentación y la formulación de leyes naturales inmutables revelan la fuerza de la inducción y la incontestabilidad de tal práctica social. Gradualmente, el saber logo-teórico cede su lugar al saber científico-matemático, la contemplación y el lenguaje común son insuficiente a los ojos de una ciencia activa y técnica. Es el advenimiento de los racionalismos y empirismos en los siglos XVI y XVII (Silveira, 2006a).

Esto sin lugar a dudas permitió desarrollar la génesis del nuevo estadio humano: la conformación de un mercado mundial que permitiera el desarrollo del capital comercial y bancario que llevó al proceso de expansión colonial europea. Conforme la infancia de la producción capitalista quedaba atrás, las necesidades mercantiles reclamaban un mayor despliegue 
mundial para su desarrollo, y al mismo tiempo conformar una base territorial sustentada en Estados-nación para operar y asegurar las relaciones de explotación y dominación ${ }^{3}$. La estrategia para alcanzar este propósito fue la de surcar el mundo entero como una medida de administración y apertura al nuevo mercantilismo tendente a la acumulación de capital, para lo cual indudablemente los postulados científicos recién fabricados serían de gran ayuda:

El descubrimiento de América y la circunnavegación de África ofrecieron a la burguesía en ascenso un nuevo campo de actividad. Los mercados de la India y de China, la colonización de América, el intercambio de las colonias, la multiplicación de los medios de cambio y de las mercancías en general imprimieron al comercio, a la navegación y a la industria un pulso hasta entonces desconocido y aceleraron, con ello, el desarrollo del elemento revolucionario de la sociedad feudal en descomposición (Engels y Marx, 2015, p.118).

En el marco de este proceso, la revolución científica de la mano de sus métodos pusieron en marcha una serie de experimentos para determinar con exactitud la dimensión y la forma de la Tierra. Las expediciones alrededor del mundo permitieron conocer con precisión la circunferencia, la magnitud y los movimientos del espacio planetario, confirmando las deducciones que proclaman los grandes científicos de la época. Además, la búsqueda por descubrir nuevos nichos de riqueza, llevó a que la expansión del poder europeo se acentuara en la navegación y la exploración de nuevas rutas, lo que sin lugar a dudas amplió el espectro científico hacia otros campos de interés.

En razón de lo anterior, las siguientes paginas exploran e indagan los principales elementos históricos, teóricos y políticos que marcaron el origen de la llamada Geografía moderna desde la exploración filosófica, epistemológica y metodológica que desarrolló la ciencia moderna y su utilidad pragmática y utilitarista en el proceso de formación del mercado mundial capitalista, en particular en el proceso de colonización. Para ello el presente artículo se encuentra estructurado en un primer momento, por el desarrollo de la revolución científica y su influenza en el campo de la

3 Véase Osorio, J. (2017). "El despliegue del capital en el Estado-nación y en el sistema mundial". Sistema mundial, intercambio desigual y renta de la tierra. Ciudad de México: División de Ciencias Sociales y Humanidades de la Universidad Autónoma Metropolitana Unidad Xochimilco/Itaca. (pp. 9-35). 
Geografía dentro del contexto de la transición de la sociedad feudal a la capitalista. Posteriormente, se analiza el papel utilitario que tuvo la Geografía en la consolidación del poder capitalista, sus tareas en el proceso de colonización y las raíces epistemológicas de su formación disciplinar. Y finalmente, se expone el nacimiento de la Geografía como una disciplina científica a la luz del desarrollo de la sociedad moderna considerando sus concepciones filosóficas, los intereses a los cuales respondieron sus saberes y las deficiencias teóricas de sus postulados disciplinarios.

\section{La revolución científica y la Geografía renacentista}

Después de siglos donde la influencia de las creencias cristianas durante la época medieval detuvo el avance y obstaculizó la difusión de la Geografía formulada por la cultura griega y el imperio romano en los albores de nuestra $\mathrm{era}^{4}$, las tempranas revoluciones científicas del siglo XVI y XVII abrieron nuevamente paso a las tareas del campo científico de la Geografía, acabando con varios siglos de divorcio entre los saberes geográficos y la comprensión del mundo natural y humano. Rápidamente, los fuertes vientos que sacudieron al pensamiento científico colocaron en un lugar privilegiado a la Geografía, debido a que varios siglo atrás había sido denominada como la ciencia dedicada al estudio de la Tierra, encargada de presentar un cuerpo formal de conocimientos orientados a la descripción y representación de los fenómenos naturales y humanos de la superficie terrestre, con el interés de descubrir los campos fértiles para el dominio comercial, político y militar.

El paulatino ascenso de la sociedad burguesa provocó nuevamente que los saberes y las prácticas geográficas fueran motivo de interés para el establecimiento de un orden social que reclamaba un saber universal y el dominio sobre todos los rincones del planeta. Se podría decir que la Geografía, desde este momento, se había constituido como la única ciencia

4 En términos epistemológicos este divorcio se debió a que el origen de la Geografía durante la Antigüedad clásica fue el de una ciencia dedicada a entender el lugar que ocupaba el ser humano en la naturaleza. Tim Unwin señala que básicamente "La descripción de la Tierra (geografía) abarcaba estudios del reino de las cosas naturales, mediaciones de la Tierra y asuntos teológicos, como el papel del poder divino en la formación de la Tierra". Además concluye expresando que "Todas estas consideraciones estaban matizadas y condicionadas por una apreciación subyacente del papel que desempeñaba la geografía en la sociedad. Este punto queda explícito en el texto de Estrabón acerca de la utilidad de la geografía [...] el uso del conocimiento acerca de lugares y gentes estaba íntimamente ligado al ejercicio del control político" (1995, pp. 82-88 [Cursiva añadida]). 
que intentó de manera consciente ser realmente mundial en su práctica, en términos de su objeto de estudio (Wallerstein, 2007, p. 29).

Las tradiciones geográficas heredadas de la sociedad grecorromana, absorbidas desde China y sobre todo del islam, fueron apropiadas y transformadas a la luz de la experiencia especifica de la Europa occidental renacentista. Para David Harvey (2007), la base inicial de los cambios en los conocimientos geográficos fueron los intercambios de mercancías, la conquista y los asentamiento coloniales, pero a medida de que evolucionó el capitalismo también el movimiento de capitales y de la fuerza de trabajo se convirtieron en el eje sobre el que giró la construcción de la nueva estructura del pensamiento geográfico.

El geógrafo español Horacio Capel señala que durante el Renacimiento "La geografía contribuyó de forma decisiva a la creación y difusión de la nueva imagen del mundo. El conocimiento de las nuevas tierras obligó a construir una nueva imagen cartográfica y descriptiva de la Tierra" (2016, p. 9). Durante esta época la Geografía se reinvento, hizo aportaciones esenciales al significado del mundo que había cambiado profundamente con los nuevos descubrimientos. La exploración y la sistematización del planeta logró definir las tareas intelectuales del conocimiento geográfico. Estos aspectos proyectaron una geografía de corte práctico, distinta a la medieval y que permitió recuperar gran parte de los pensamientos clásicos. Sin embargo, ante la velocidad de los acontecimientos, los conocimientos geográficos se reformularon con la intención de mostrar los novedosos planteamientos que la revolución científica proporcionaba, atestiguando sobre todo el uso imperioso de las matemáticas, la astronomía y la física como sustento científico.

A diferencia de los temas centrales de la Geografía del periodo clásico, durante el Renacimiento y el nacimiento de la ciencia moderna, la Geografía al perder parte de su sentido filosófico y teológico, fue dejando de lado el interés por los asuntos acerca del origen de la vida y la naturaleza, en particular, el lugar que correspondía a la humanidad dentro del mundo natural ${ }^{5}$. Es así como finalmente la elaboración de inventarios, en los cuales se describen los "atributos" naturales de los lugares descubiertos, y la fabricación de mapas para la navegación serán los aportaciones de

5 Para conocer más sobre las características de la llamada geografía clásica véase Ortega, J. (2000). Los horizontes de la geografía. Barcelona: Ariel. (pp. 35-61). 
la geografía al desarrollo de la ciencia y al naciente poder capitalista. De forma que proliferaron los estudios topográficos sobre lugares concretos, incluyendo descripciones de tierras, costas y puertos lejanos, donde se versaba una mirada corográfica del planeta. También se hizo presente la tradición por las mediciones de la Tierra y su relación con el universo a partir de la astronomía y las matemáticas. Finalmente, la cartografía, con fuentes y técnicas de mayor precisión, proporcionó una base detallada sobre los viajes de descubrimiento, lo que significó una nueva forma de descripción del nuevo mundo. Estos temas dieron un fuerte impulso a la Geografía al ser esenciales para los comerciantes y políticos, al formar los pilares sobre los cuales las naciones europeas dominaban el globo.

Finalmente, la Geografía logra incursionar en el proyecto científico de esta época a partir de la obra del alemana Bernhardus Varenius, mejor conocido como Varenio. Bajo el ropaje y el lenguaje de la revolución científica del momento, Varenio vuelve a clasificar al conocimiento geográfico en dos grandes unidades: entre una geografía general que, mediante la formulación de leyes, logra medir y conocer la superficie de la Tierra, y una geografía especial que describe y delimita porciones de la superficie terrestre. Tal dualismo, reavivó las tensiones epistemológicas y metodológicas que tuvo la Geografía en su orígenes, entre las propuestas de Geografía descriptiva, regional e histórica de Estrabón frente a la Geografía astronómica, general y global de Ptolomeo. La ruptura entre las dos formas de saber, general y singular, se expresaron en la propuesta de Varenio quien sostuvo a grandes rasgos una Geografía divida en dos partes, la primera encargada de las características y aspectos generales de la Tierra, y la segunda que estudia las regiones concretas, su localización, divisiones, limites y otros aspectos. De manera que, a partir las leyes generales de la Tierra, se busca reconocer las cualidades y diferencias de los distintos lugares. Esta propuesta se convierte en la carta de presentación de la Geografía en el mundo científico, en donde las leyes generales de la ciencia moderna son integradas a la metodológica geográfica como cuerpo dominante de sus postulados, lo que sin lugar a dudas marcará el futuro de la ciencia:

Alió (Varenio) la geografía general a los métodos científicos clásicos y sostuvo que las pruebas debían conducirse mediante argumentaciones o 
demostraciones lógicas, de forma similar a lo que ocurría en las matemáticas y la geometría. Por el contrario, en la geografía especial, sugirió que $<<$ todo se explica casi sin necesidad de demostración (excepto las características celestes que pueden demostrarse), puesto que la experiencia y la observación, es decir, el testimonio de los sentidos, son suficientes para confirmar la mayoría de las cosas, que es imposible demostrar de otro modo $>>$ (Unwin, 1995, p.105).

El papel relevante de la Geografía durante esta época no acabó ahí. La importancia que adquiere el capital comercial durante el Renacimiento contribuyó a acelerar la disolución del modo de producción feudal, lo que se manifiesta en el aumento de la importancia del dinero en el desarrollo de la producción mercantil y en la quiebra de las viejas instituciones medievales, que comienzan a ser reemplazadas por la centralización política de las monarquías absoluta (Marini, 1983). Para lograr este propósito, los conocimientos, las representaciones y la información geográfica jugarán un papel fundamental en el formación del absolutismo en cuya definición se encuentra la clave de su atribución geográfica:

Estado fuertemente centralizado [...] fuente de todo poder "político" en el interior de un dominio territorial-nacional. [...] Así se forma progresivamente la noción de soberanía del Estado: expresa el dominio institucionalizado exclusivo y único, propiamente público, sobre un conjunto territorial-nacional y el ejercicio efectivo central sin las restricciones "extrapolíticas" de orden jurídico, eclesiástico o moral que caracterizaban al Estado feudal. Esa soberanía del Estado se manifiesta, por lo demás, también hacia el exterior y autoriza al monarca a ser en las relaciones internacionales su único árbitro: hecho nuevo si se recuerda el papel que desempeñaba, por ejemplo, la Iglesia en las relaciones entre Estados feudales. En resumen, el carácter fundamental del Estado absolutista es representar la unidad propiamente política de un poder centralizado sobre un conjunto nacional, al contrario de una fragmentación y de una parcelación del poder en dominios territoriales (Poulantzas, 1976, pp. 205-206.

Esta doble cualidad geográfica del absolutismo -centralidad/expansión -, es una dimensión que además de novedosa, sienta las bases del sistema mundial capitalista y la edificación de su propio Estado moderno. Configura las relaciones entre las metrópolis y las colonias, el centro/ 
periferia, en un mundo que a partir del Renacimiento no cesará de convertirse cada vez más en un mundo contradictoriamente unificado. En palabras de Carlos Walter Porto Gonçalves el transito de la Edad Media a la Edad Moderna, en el Renacimiento, se trataba de construir nuevas marcas en la tierra, de fijar los nuevos limites de las nuevas comunidades de destinos humanos, de delimitar los espacios, es decir, de construir territorios, los estados territoriales modernos, lo que significa un proceso histórico de reorganización del espacio geográfico y la sociedad:

El Renacimiento marca el comienzo de un forma de organización social en la que, con la centralización del poder político en las monarquías centralizadas, el poder local y los hombres en su espacio de vida cotidiano, los siervos/campesinos en primer lugar, pero también, un buen número de señores, y en estos casos la cuestión regional gana mayor importancia, pierden el poder de determinar su organización espacial. Es de este modo como podemos percibir mejor que el proceso de reorganización social que emerge a partir del Renacimiento fue, concomitantemente, un proceso de reorganización espacial en el que el geógrafo es no sólo un protagonista de esas reorganización sino, también, parte del proceso de reorganización social, en tanto comunidad científica que, dentro de ese contexto, cobra sentido (Porto Gonçalves, 2001, pp.19-20) ${ }^{6}$.

De manera que no es producto de la casualidad, que el origen de la palabra geógrafo aparezca por primera vez en la lengua francesa y portuguesa en 1537 y designa, del siglo XVI al XVIII, a aquellos que construyen mapas y, a veces, los comentan. Son los llamados geógrafos del rey (Ibid., p.17). En síntesis, la Geografía que nace del Renacimiento y bajo los reflectores de la revolución científica adquirirá un estatus de ciencia al servicio de las causas de expansión capitalista, ligada a la burguesía y como un instrumento de Estado. Los "descubrimientos" de nuevas tierras obligaron a modificar las ideas sobre el mundo, la Geografía coadyuvo notablemente en dicha tarea con la producción de mapas y la elaboración de inventarios.

6 Las marcas en la tierra a las que remite Porto Gonçalves, refieren etimológicamente al significado de la palabra Geo-grafias. Elocuente noción utilizada por el geógrafo latinoamericano. Para conocer más detalles sobre ella véase en el mismo texto. 


\section{La Geografía en los albores de la expansión capitalista}

El siglo XVIII, el siglo de las luces, será decisivo para el desarrollo de la ciencia y la Geografía. Durante este siglo, la Ilustración expresará todas las aspiraciones de una nueva sociedad que a su modo busca abiertamente disipar las tinieblas de la ignorancia de la humanidad mediante las luces del conocimiento y la razón. Sin embargo, en realidad con este siglo se inicia la era de la violencia mas brutal. Como lo indica Rosa Luxemburgo (1967, p. 288), con el hace su aparición el método capitalista específico de colonización. Para K. Marx el sistema colonial de esos años se funda en el poder del Estado, en la violencia organizada y concentrada de la sociedad, para fomentar como un invernadero el proceso de transformación del modo de producción feudal en modo de producción capitalista y para abreviar las transiciones. La violencia es la partera de toda sociedad vieja preñada de una nueva. Ella misma es una potencia económica. El sistema colonial hizo madurar el comercio y la navegación. Los tesoros expoliados fuera de Europa directamente por el saqueo, por la esclavización y las matanzas con rapiña, refluían a la metrópoli y se transformaban allí en capital (Marx, 2008, pp. 940-943). Es así como los chorros de lodo y sangre que acompañan la llegada del capitalismo al mundo se cubrieron bajo los mitos del pensamiento Ilustrado y su tan anhelado progreso.

Para llevar a cabo tal proceso histórico, fue necesario imprimir nuevas ideas al mundo científico que permitieran validar, justificar y legitimar el orden de las cosas. Desde los primeros minutos del siglo XVIII, la mistificación feudal del mundo dejó completo paso a lo que sería el empirismo y el racionalismo como fuentes de dominación de la naturaleza y la sociedad. Las ideas filosóficas que dieron vida a estos principios fueron desarrolladas por Rene Descartes y Immanuel Kant, el primero como punto de partida de la filosofía moderna y el segundo como progenitor del proyecto moderno de ciencia. Estos dos pensadores darán vida al pensamiento moderno, cuyos preceptos se basan en los principios ideológicos cientificidad y racionalismo. Esta convicción compartida presenta, desde la perspectiva de la interpretación, es decir desde la ciencia y la filosofía, un proceso de conocimiento de la realidad objetiva a través de distintas formulaciones complementarias.

Lo anterior tiene como base la interpretación de que el conocimiento vendrá de la racionalidad del comportamiento humano y la confianza 
en la experiencia. La fuente de este movimiento de fundación de la ciencia moderna se hallará en el dualismo cartesiano. Una forma de filosofía empírica del conocimiento racionalista. Edgar Morín califica a este como el $<<$ gran paradigma de Occidente $>>$ e impuesto por los desarrollo de la historia europea:

El paradigma cartesiano separa al sujeto del objeto con una esfera propia para cada uno : la filosofía y la investigación reflexiva por un lado, la ciencia y la investigación objetiva por el otro. Esta disociación atraviesa el universo de un extremo al otro. Sujeto/objeto; Alma/Cuerpo; Espíritu/ Materia; Calidad/Cantidad; Finalidad/Causalidad; Sentimiento/Razón; Libertad/Determinismo; Existencia/Esencia. [...] Determina los conceptos soberanos y prescribe la relación lógica : la disyunción. La no-obediencia a esta disyunción sólo puede ser clandestina, marginada, desviada. Este paradigma determina una doble visión del mundo, en realidad, un desdoblamiento del mismo mundo: por un lado, un mundo de objetos sometidos a observaciones, experimentaciones, manipulaciones; por el otro, un mundo de sujetos planteándose problemas de existencia, de comunicación, de conciencia, de destino (Morín, 1999, pp.9-10).

Racionalismo y empirismo serán dos caras de la misma moneda. En el primer caso, se pone el acento en la razón humana como herramienta ordenadora de las experiencias. Es la capacidad lógica de la mente la que hace inteligible el mundo de las experiencias. En su expresión más radical, ubica el orden natural en la razón. En el segundo, se hace hincapié en la primacía de la experiencia como fuente del conocimiento. Son los datos de los sentidos, las percepciones, los que permiten el conocimiento objetivo, los que proporcionan el orden natural (Ortega, 2000, p. 189). Por su parte, Kant ofrecerá una solución a esta falsa dicotomía. Para él la opción entre empirismo y racionalismo era irreal, las dos filosofías se equivocan en sus planteamientos; por su parte señala que la única metafísica concebible que podía encomendarse a un ser razonable debía ser tanto empírica como racionalista (Unwin, 1995, p. 107).

En el recorrido planteado, cobró plena vigencia para la naciente ciencia moderna la exigencia de relacionar al pensamiento con el mundo sensible, a través de la experiencia reivindicando a ésta como criterio último de verdad. Esta lucha de la filosofía renacentista en contra de la escolástica caracterizó el desarrollo de las ciencias naturales y, con ella, 
de un concepto de objetividad y verdad que se encontraran en la base de la idea del método. Fue en esta línea que el método de la ciencia natural debía desarrollarse a partir de las matemáticas y vinculando en todo momento a la teoría con la experiencia a través de la observación controlada en el experimento y buscando establecer leyes universales. Se trataba de extender la certeza de las matemáticas al conjunto del saber humano dando lugar a un ciencia universal. Así, todos los fenómenos de la naturaleza debían poder ser explicados conforme a leyes partiendo de las figuras y de los movimientos tal y como éstos habían sido analizados por las matemáticas, especialmente por la geometría. Surge la necesidad de elaborar un método para acceder a la verdad. Los principios de un método semejante se considera ahí válidos para conducir al espíritu a la verdad en todos los ámbitos del saber humano. Fue en el marco de esta respuesta que se desplegará en las décadas siguientes una intensa disputa entre el racionalismo y el empirismo, cuya salida llegará a mediados del siglo XIX cuando se imponga la idea de la prueba empírica cuantitativa para fundamentar la verdad (De la Garza y Leyva, 2010).

Esta exposición tendrá impactos extraordinarios en la Geografía, a la vez que sellará la concepción de espacio como categoría a priori del pensamiento (Silveira, 2006a, p. 10). Tal concepción reflejará fielmente uno de las más significativas influencias filosóficas para la ciencia moderna y en este caso particular para la Geografía. Las ideas y las obras kantianas referentes a la ciencia geográfica fueron de gran impacto, además de ser profesor de geografía y elaborar tratados con una gran cantidad de información de este campo de estudio, su principal obre en este ámbito fue Geografia Física publicada en 1803. Sin lugar a dudas sus propuestas más destacadas para este campo de conocimiento fue el método para conocer la dimensión geográfico-espacial y, por otro lado, la definición científica que hace de la ciencia geográfica. Sobre el primer de estos puntos, trataría de entenderse que en su pensamiento, la clasificación de las percepciones empíricas podían organizarse lógicamente, según conceptos, o físicamente, según el tiempo y el espacio en el que se encuentran realmente: por la primera se obtiene un sistema de la naturaleza y, por la segunda, una descripción de la naturaleza (Capel, 2016, p. 13). Entre tanto. para el segundo de los punto, Moraes señala que respecto a su concepción de geografía y 
el lugar que le asigna en la esfera del conocimiento, para Kant el estudio geográfico trataría de:

describir todos los fenómenos manifestados en la superficie del planeta, siendo una especie de síntesis de todas las ciencias. Esta concepción se origina en las formulaciones de Kant. Para este autor, habría dos clases de ciencias, las especulativas, apoyadas en la razón y las empíricas apoyadas en la observación y en las sensaciones. A nivel de las segundas, habría dos disciplinas de síntesis, la Antropología, síntesis de los conocimientos relativos al hombre, y la Geografía, síntesis de los conocimientos sobre la naturaleza. De esta forma, la tradición kantiana coloca a la Geografía como una ciencia sintética (que trabaja con datos de todas las demás ciencias), descriptiva (que enumera los fenómenos abarcados) y que trata de abordar una visión de conjunto del planeta. Las mayores polémicas provocadas por esta perspectiva, denominada corológica (visión espacial, en oposición a la cronológica o enfoque temporal), hablan respecto del significado preciso de la superficie terrestre (Moraes, 2006, p. 6).

Es evidente que durante esta etapa, y en adelante, este criterio de cientificidad y de pensamiento ilustrado en realidad, mostró como la burguesía de aquella época, aplicó un principio racionalista para ordenar sus propios negocios y otro irracionalista para ordenar el contexto social y económico global (Bagú, 1980). A decir de Adolfo Gilly, las grandes conquistas del Iluminismo, las conquistas humanas de la ciencia y el pensamiento racional, fueron trasmutadas en dispositivos prácticos para cuantificar, clasificar, medir y mecanizar en nombre de la permuta, el trueque y el intercambio, mediados por el dinero como encarnación de la esencia de las relaciones humanas; y para crear nuevas formas de mando sobre los seres humanos y nuevas formas de guerra contra los enemigos de abajo o afuera (2013, p. 53).

Sin lugar a dudas estos nuevos pensamientos permearon en lo más profundo del conocimiento geográfico, debido a los intereses comerciales, expansionistas y colonizadores que la naciente burguesía ilustrada tenía frente al "descubrimiento" del nuevo mundo y la necesidad de encontrar una justificación a su dominio territorial. Esto abrió la posibilidad de organizar $<<$ racionalmente $>>$ el espacio para la acumulación de capital, de dividir el espacio con fines de administración eficiente o con el objetivo de mejorar la 
salud y el bienestar de la población (el sueño de la Ilustración incorporado a la planificación racional del bienestar humano), (Harvey, 2007).

Como primer resultado de lo anterior, se consagró una geografia ilustrada basada en la construcción de una nueva forma objetiva y racional de mirar el mundo. Esta geografía, fundada en el empirismo más ingenuo7, se encargó de "describir rasgos físicos, químicos y biológicos de la corteza terrestre a manera del naturalismo"(León, 2016, p. 18). Es una geografía fundamentalmente pragmática y utilitarista. La elaboración de monografías que contribuyeron a los conocimientos enciclopédicos y el perfeccionamiento cartográfico, dieron a los saberes geográficos un sentido más práctico que al de épocas anteriores. Debido a su notable utilitarismo, la Geografía mantuvo su presencia y estatus en el mundo científico a pesar del surgimiento de nuevas disciplinas científicas mucho más especializadas y con mayor solidez experimental, sobre todo en el campo de las ciencias naturales, las cuales comenzaron a invadir el propio "objeto de estudio" de la Geografía. Además, el vinculo orgánico de los saberes y prácticas geográficas con las estructuras del poder político se conservó e inclusive llegó a reforzarse.

Como resultado de este desarrollo, los conocimientos geográficos dieron un giro fundamental en su estructura epistemológica con la llega de la sistematización de la geografía (Moraes, 1987), en tanto génesis de su fase moderna, cuya obra estuvo a cargo de dos naturalistas alemanes, Alexander von Humbolt, considerado el padre putativo de la geografía moderna, y Carl Riiter. Representante del idealismo y romanticismo alemán, Humbolt dotó de cientificidad la mirada universal de la naturaleza concebida como un todo de partes íntimamente relacionadas, un todo armonioso movido por fuerzas internas. Hizo de la observación, y de los principios causalidad y la descripción sus instrumentos metodológicos de interpretación, cuyo resultado fue un empirismo racional. Pone en marcha

7 Jaime Osorio caracteriza la noción del empirismo ingenuo de la siguiente manera "en ciencia sociales el camino más corto para llegar a conocer no pasa por enfrentarse a la realidad sin más, como supone el empirismo. Esta posición elude la mediación central referida a los problemas de cómo nos paramos frente a la realidad social, cómo la interrogamos, cómo leemos e interpretamos sus respuestas e incluso cómo se construye el dato y la información.[...] A cuestionar las evidencia del sentido común. A tomar la realidad con el cuidado que merece. A considerar el propio proceso de construcción de los datos, de los hechos, como un problema teórico y metodológico. Que no hay datos dados de por sí”. Al final de su comentario cita en el mismo texto unas palabras de N. R. Hanson que terminan exponiendo muy ad hoc lo que es justamente este empirismo para la geografía, en definitiva "hay mucho más que ver que lo que entra por el ojo". (Osorio, 2016, p. 12-13). 
un proyecto de geografía física global en el marco de las ciencias empíricas, acorde con el pensamiento científico de su época:

Se corresponde con lo que el denomina descripción física de la Tierra. Ámbito en el que consideraba posible la construcción de un campo de conocimiento empírico riguroso. Proyecto que aparecía como factible en la medida en que los fenómenos y procesos que caracterizan la dinámica de la superficie terrestre, desde los geológicos a los biológicos, podían ser abordados desde postulados metódicos y teóricos acordes con las exigencias de la nueva ciencia. La geología, la hidrología y oceanografía, la botánica y la zoología tenían ya bases consistentes y un perfil moderno. Eran disciplinas desarrolladas sobre la base de una sistemática observación empírica, articuladas sobre hipótesis y formulaciones teóricas más o menos explicitas. Disponían, en todo caso, de una sistemática clasificatoria sólida, la clasificación lógica de Kant, formaban parte de los «sistemas de la naturaleza». [...] Una Geografía Física que se asienta, sin lugar a dudas, en un marco epistemológico positivo, con un estatuto científico explícito, por encima de la simple clasificatoria, como Humboldt precisaba al separar su disciplina de los conocidos como «sistemas de la Naturaleza»: «El objeto de la Geografía Física es, por el contrario, como hemos dicho antes, reconocer la unidad en la inmensa variedad de los fenómenos y descubrir, por el libre ejercicio del pensamiento mediante la regularidad de observaciones, la regularidad de los fenómenos dentro de sus aparentes variaciones. »(Ortega, 2000, p. 129).

Por su parte, la obra de Ritter a diferencia de Humbolt, propuso de una manera directa y fundamental el estudio de las relaciones entre la superficie terrestre y la actividad humana. La atención se centraría ahora en el hombre, la Tierra pasa a ser objeto de una atención secundaria que, sobre todo, aparece en cuanto que es el $<<$ teatro $>>$ de la vida humana (Capel, 2012, p. 51). Así, la Geografía de Ritter es, principalmente, un estudio de los lugares, una búsqueda de la individualidad de éstos. Toda esta propuesta se asentaba en la arraigada perspectiva religiosa de este autor. Para él, la ciencia era una forma de relación entre el hombre y el "creador" (con una dimensión interior de revelación), una tentativa de perfeccionamiento de las acciones humanas, una aproximación a la divinidad.

En este sentido, cabría a la Geografía explicar la individualidad de los sistemas naturales, pues en ésta se expresaría el designio de la divinidad 
al crear aquel lugar específico. La meta sería llegar a una armonía entre la acción humana y los designios divinos, manifiestos en la variable naturaleza de los medios. Como lo reconocer Robert Moraes "La propuesta de Ritter es, por estas razones, antropocéntrica (el hombre es el objeto de la naturaleza), regional (apunta al estudio de individualidades), valorizando la relación hombre- naturaleza. En términos de método, Ritter va a reforzar el análisis empírico - para él, es necesario avanzar de "observación en observación" (Moraes, 2006, p. 18).

\section{Los orígenes burgueses de la Geografía moderna}

Entre los últimos años del siglo XVIII y la primera mitad del XIX, el mundo vivió la mayor transformación en la historia humana desde los remotos tiempos en que los hombres inventaron la agricultura y la metalúrgica, la escritura, la ciudad y el Estado. Esta revolución transformó y sigue transformando al mundo entero. La gran era de la revolución de 1789-1849 no fue el triunfo de la $<<$ industria $>>$ como tal, sino de la industria $<<$ capitalista $>>$; no de la libertad y la igualdad en general, sino de la sociedad $<<$ burguesa $>>$ y liberal; no de la $<<$ economía moderna $>>$, sino de las economías y estados en una región geográfica particular del mundo (parte de Europa y algunas regiones de Norteamérica), (Hobsbawm, 2009). La primera de las revoluciones burguesas, la industrial, como lo narra el propio Eric Hobsbawm (2012) en su clásico texto La formación de la clase obrera en Inglaterra, llevó a que los recientes instrumentos físicos de producción dieran lugar, de forma directa y más o menos compulsiva, a nuevas relaciones sociales, instituciones y formas culturales. Por su parte, el logró de la Revolución Francesa fue sentenciar y cristalizar todas las aspiraciones construidas en el marco de los anhelos civilizatorios e ilustrados: el reino de la igualdad y la libertad.

Por tales circunstancias, la revolución industrial y la revolución francesa se podrán señalar como los dos grandes hitos que definieron el triunfo de la sociedad liberal y burguesa. Tras esta victoria, Karl Marx y Friedrich Engels escribirían el Manifiesto del Partido Comunista, declaración de guerra del proletariado escrito hace ciento setenta años. El Manifiesto, plasmaría dentro de sus paginas una serie de revelaciones teóricas y políticas sobre el desarrollo de la sociedad moderna, su carácter contradictorio y los inevitables estragos que acompañarían su trayectoria. En uno de 
los pasajes más recordados hasta nuestros días, debido al pronóstico tan acertado que hoy se revela en su máximo esplendor ante nuestros ojos, se describía el carácter universal y totalizador del capitalismo, ilustrado en aquellas memorables palabras: "Espoleada por las necesidad de dar cada vez mayor salida a sus productos, la burguesía recorre el mundo entero. Necesita anidar en todas partes, establecerse en todas partes, crear vínculos en todas partes [...] forja un mundo a su imagen y semejanza" (Engels y Marx, 2015, pp. 120-121 [Cursiva añadida]). Esta última afirmación, expondrá y sintetizará categóricamente la unificación de todas las relaciones entre los seres humanos bajo una misma concurrencia mercantil y permitirá determinar la norma común que regulará la convivencia entre los individuos en esta fase de la historia.

La configuración de este orden social a nivel mundial, supuso, como tendencia del pensamiento dominante, la universalización de los conocimientos y los saberes modernos, los cuales adoptarían la forma de lo que hoy lleva el nombre de ciencias sociales y humanidades. Fue así que las ideas y la concepción de mundo de la sociedad capitalista se tradujo de la siguiente manera:

Las distintas sociedades que registra la historia antes del advenimiento del capitalismo correspondían a formas sociales más simples, basadas en una estructura de clases poco diferenciada y muy estratificada, que se expresaba en sistemas políticos centralizados y autocráticos. Pensemos en los regímenes teocráticos o feudales y, en general, en sociedades cuya producción era asegurada por relaciones esclavistas o de servidumbre. Desde luego, en el sostenimiento de esos sistemas de dominación desempeñaba papel destacado el uso de la fuerza. [...] En comunidades más simples, como las que mencionamos antes, se tiende a recurrir, en este sentido, a lo sobrenatural, privilegiando a la religión, o a diferencias evidentes, de carácter racial o cultural. En organizaciones sociales más complejas, el razonamiento se sofistica y aspira a presentarse como ciencia. [...] Ello se dará con más razón aún cuando el capitalismo, rompiendo el orden feudal, pase a conformar Estados nacionales. Estos corresponden a sociedades de clases altamente complejas, cuya lógica - aunque consagre la dominación de unas sobre otras y repose siempre en la fuerza - es la de recurrir crecientemente a los mecanismos económicos y a la persuasión ideológica como resortes de dominación. En la medida en que el capitalismo se consolide, la burguesía tratará, por un lado, de asumir el monopolio absoluto del poder político y, 
por otro, de afirmar su hegemonía sobre la clase obrera y demás sectores sociales (Marini, 1994 [Cursiva añadida]).

Sintetizando lo anterior, la construcción de la ciencia moderna para la sociedad burguesa capitalista es un conjunto de interpretaciones y significados del mundo que, lejos de revelar y captar la esencia de la realidad, norman el respeto irrestricto de las reglas de juego de la sociedad burgue$\mathrm{sa}^{8}$. Así, el acento de la desviación desde la ciencia a la religión y al misticismo natural ocurrió en un contexto de una función de legitimación de la explicación en una sociedad clasista. La burguesía tenía que descubrir el mundo y simultáneamente ocultar su explotación. La ciencia adoptó su apariencia mística cuando la conciencia o el propósito entraron en el escenario de la historia. Como ello sucedió a menudo en la fase imperial, la tendencia a la desviación mística fue particularmente clara en el desarrollo científico de la época (Peet, 2012, p. 121[Cursiva añadida] ).

La conquista de la razón hizo que la ciencia moderna se definiera como la búsqueda de leyes naturales universales, lo que significó que las bases newtonianas y cartesianas que definían a las ciencias naturales, consolidadas décadas atrás, fueran catalogadas como las únicas fuentes de verdad y sabiduría. El conocimiento objetivo de la realidad con base en descubrimientos empíricos distanció gradualmente a las ciencias naturales de la filosofía y otras formas de conocimiento calificadas como "especulativas" o "intuitivas". Al institucionalizar el conocimiento en las universidades durante el siglo XIX, en medio del ruptura antes señalada, la ciencias naturales rápidamente y sin contratiempos se constituyeron formalmente y de manera precisa. Contrario a esto, todo lo que se

8 En referencia a esto, Karel Kosik sostiene que "En virtud de que la esencia -a diferencia de los fenómenosno se manifiesta directamente, y por cuanto que el fundamento oculto de las cosas debe ser descubierto mediante una actividad especial, existen la ciencia y la filosofía. Si la apariencia fenoménica y la esencia de las cosas coincidiera totalmente, la ciencia y la filosofía serían superfluas". (1976, p.29).

9 Al respecto Immanuel Wallerstein menciona que "Al principio los que intentaban establecer la legitimidad y prioridad de la búsqueda científica de las leyes de la naturaleza no hacían mayor distinción entre ciencia y filosofía. En la medida en que distinguían los dos dominios pensaban en ellos como aliados en la búsqueda de la verdad secular, pero a medida que el trabajo experimental y empírico pasó a ser cada vez más importante para la visión de la ciencia, la filosofía comenzó a aparecer para los científicos naturales cada vez más un mero sustituto de la teología, igualmente culpable de afirmaciones a priori de verdades imposibles de poner a prueba. [...] Finalmente, en el inicio del siglo XIX el triunfo de la ciencia fue consagrado por la lingüística: el termino ciencia, sin adjetivo calificativo, pasó a ser identificado principalmente (y a menudo exclusivamente) con la ciencia natural. Ese hecho marcó la culminación de la ciencia natural de adquirir para sí misma una legitimidad socio-intelectual totalmente separada e incluso en oposición a otra forma de conocimiento llamada filosofía". (2007,p.7) 
manifestaba como expresión del generó humano, y que por lo tanto no era considerado científico debido al fuerte sesgo deductivo y contemplativo al cual apelaba, tuvo que aprehender los esquemas de la ciencia positiva para abrirse paso en los nuevos espacios de conocimiento, lo que llevo a su impronta constitución de asumir leyes generales y formas tangibles de comprensión de la vida social.

Así es como la ciencia social a decir de Wallerstein es una empresa del mundo moderno donde "sus raíces se encuentran en el intento, plenamente desarrollado desde el siglo XVI y que es parte inseparable de la construcción de nuestro mundo moderno, por desarrollar un conocimiento secular sistemático sobre la realidad que tenga algún tipo de validación empírica." (2007 p. 4 [Cursiva añadida]). Para asumir dicha condición fue necesario una división de los modos de conocer el comportamiento humano. Una época triste donde el hombre fue cortado en rodajas por parte de las nacientes ciencias humanas (Morín, 2010). Los conocimientos sociales fueron clasificados disciplinariamente $o$ mejor dicho disciplinadamente de acuerdo a sus posiciones epistemológicas y por lo tanto sus "objetos" de estudio. La conformación de las ciencias sociales formó parte del reduccionismo del pensamiento moderno ${ }^{10}$. El resultado fue una multiplicación de conocimientos disciplinarios en el seno de las propias ciencias dedicada al estudio de la sociedad: por un lado nacieron las ciencias ideográficas allegadas a las humanidades empezando por la filosofía, cuya clasificación esta dada por su interés en lo particular, lo especifico y lo singular de los objetos de su interés, aquí se encuentra la historia, la antropología y los estudios orientales; por el otro lado están las ciencias nomotéticas más cercanas a las ciencias naturales, cuya objetivo es la formulación de leyes generales para la explicación de los fenómenos sociales, aquí se encuentran la economía, la sociología y la ciencia política. Al respecto, Jaime Osorio concluye señalando que el pensamiento moderno es:

un pensamiento sobre cosas. Las ciencias sociales que se construyen desde esta perspectiva no pueden abstraerse de este fundamento. Ello es debido a la impronta empirista y experimental que caracteriza tendencialmente

10 Esta noción es planteada por Jaime Osorio de la siguiente manera "El supuesto de fondo es que existen problemas - o hechos- autónomos o puramente económicos, o políticos, o sociológicos, etc., lo que significa la conformación de disciplinas autónomas a su vez, con objetos particulares y metodologías y técnicas específicas para abordarlos". (2016, p. 45). 
a este pensamiento, y a las ciencias sociales que termina conformando, las cuales hacen de las cosas su objeto de observación y experimentación (Osorio, 2016, pp. 41-42).

Por lo tanto, fundadas en el método experimental, las denominadas ciencias de la naturaleza inician su camino ascendente de descubrimiento de las dinámicas del la naturaleza y de formulación de leyes. Un ir y volver de la realidad al laboratorio asegura los fundamentos de su cientificidad. Mientras, los saberes históricos comienzan a liberarse de la estrategrama de lo único o lo general, a partir de la idea del movimiento de la razón. Sin embargo, como lo señala la geógrafa argentina María Laura Silveira (2006b), la geografía parece quedar a mitad del camino. Bajo este hito, las primeras cátedras de geografía y la fundación de las primeras sociedades geográficas en el inicio del siglo XIX, marcaran la institucionalización de la disciplina en la universidades alemanas. Este episodio quedó marcado por la indefinición epistemológica y ontológica que tuvo la geografía en la naciente estructura de la ciencia moderna. Los postulados empiristas y naturalistas de la geografía sistematizada, que serían la base de la geografía moderna o también conocida como tradicional, fueron un lastre frente a los nuevos esquemas de conocimiento, por lo cual fue necesario adaptar sus propuestas a los estándares disciplinarios de la época. Para integrarse y sobrevivir a las divisiones intelectuales de las ciencias sociales la Geografía tuvo que rehacer su objeto de estudio, la relación entre el medio físico y el ser humano se convirtió en su apuesta disciplinar. De manera que "a la descripción empirista y utilitarista de los rasgos físicos, químicos y biológicos tan solo vendría a agregarse la de los rasgos de los grupos humanos"(León, 2016, p. 19).

Lo anterior llevó a que la geografía se autonombrara como una ciencia puente entre las ciencias naturales y las ciencias sociales. La Geografía sería vista como una ciencia de síntesis o mejor dicho de una concepción truncada del todo (Moreira, 2017, p. 48). Este planteamiento se alimenta en el afán clasificatorio del positivismo. Particularmente, la Geografía se llenaría de una enorme soberbia al considerarse como la culminación del conocimiento científico, esto es:

como la disciplina que relacionaría y ordenaría los conocimientos producidos por todas las demás ciencias. Seria una especificidad misma del 
análisis geográfico trabajar con el conjunto de fenómenos que componen lo real, lo que abarcaría desde aquellos temas de la física, hasta los del dominio de la economía o de la antropología. Entonces, todo entraría en el análisis geográfico, que de esta forma tendería a ser exhaustiva en términos de los elementos abarcados. Todo aquello que interfiere en la vida de la superficie de la Tierra sería plausible de integrarse al estudio. [...] Esta concepción atribuye a la Geografía un carácter antisistemático, que la distinguiría de las demás ciencias, siendo por excelencia un conocimiento sintético, que unificaría los estudios sistemáticos efectuados por las demás ciencias. En verdad, la idea de "ciencia de síntesis" sirvió para encubrir la vaguedad y la indefinición del objeto. Tal idea, que postulaba un conocimiento excepcional, desvinculaba tal ciencia de una exigencia del propio positivismo - la definición precisa del objeto de estudio. Así, esta máxima servía para legitimar el estudio geográfico en base a un fundamento, del cual no se cumpliría una exigencia central (Moraes, 2006, p. 10).

La Geografía moderna se extiende por lo tanto como un conjunto científico híbrido por la existencia de dos troncos básicos dedicados al examen de diversos aspectos naturales y sociales inconexos entre sí. Una catalogación y un inventario monográfico de la descripción de las regiones del planeta que llevaran el nombre de geografía física y geografía humana. Una criatura malformada: una niña bicéfala o dos gemelos siameses, unidos por la espalda y con personalidades encontradas llamados Geografía (Uribe, 1998, p. 15). La geografía física aparece en todo momento como la hermana mayor (Ortega, 2000), será la capa superior del análisis geográfico, con esto se buscaba dar un mayor sustento científico a la propuesta, mientras en términos políticos se legitima o se explican los procesos sociales a partir de la causas naturales ${ }^{11}$. Esta situación llevo a que dentro de la propia división de las ciencias sociales la geografía quedará en el limbo de dicha estructura: la explicación de los fenómenos naturales mediante leyes generales la orientó hacia las ciencias nomotéticas, en cambio el conocimiento particular de comunidades, regiones y grupos humanos en referencia a la descripción de sus modos de vida la acercó al mundo de las ciencias ideográficas. En lugar de representar un atributo al intentar romper con la forma dominante de conformación del saber moderno reduccionista, la Geografía se metió en un callejón sin salida, donde la famosa

11 Lo que en palabras de Richard Peet (2012) esto se podría traducir en una ideología legitimadora y explicativa del desarrollo capitalista desde el determinismo. 
síntesis geográfica lejos de proporcionarle una buena referencia dentro de la composición disciplinar le generó una manía de grandeza y pretensión insoportable que la alejo del resto de las disciplinas.

Para el geógrafo brasileño Milton Santos, dicho estereotipo y etiqueta autoimpuesta pasa por hacer de la Geografía una ciencia de síntesis, es decir, capaz de interpretar los fenómenos que ocurren sobre la faz de la tierra, utilizando para ellos un instrumental proveniente de múltiples ramas del saber científico tanto en el ámbito de las disciplinas naturales y exactas, como de las disciplinas sociales y humanas, aun y cuando hasta el día de hoy jamás pudo desarrollar el instrumental necesario para alcanzar la susodicha síntesis. Piensa que es una tontería reservar un papel tan importante a una sola disciplina. Así, la Geografía se consideró a si misma como la única disciplina capaz de realizar dicha síntesis, para lo cual un buen número de ciencias contribuirían a dicho objetivo, las llegaría a denominar sus muletas, meras ciencias auxiliares. Esto haría de los geógrafos el jefe de la orquesta mientras que los demás científicos solo son los músicos (Santos, 1990, pp. 113-116).

Esto pasó por la incapacidad de explicar la conexión de dos universos distintos a través del método experimental y al mismo tiempo empírico como los que rigen a la ciencia moderna. Esto engendró el mito de la unidad geografía (Reynaud, 1976). Así como en su momento la filosofía de Descartes y Kant influenció de sobremanera la sistematización de la Geografía décadas atrás, el pensamiento de Comte, Durkheim y Darwin nutrieron a la Geografía moderna. Quizás esta situación hubiera cambiado radicalmente si la esencia unificadora de la Geografía, en lugar de fundarse dentro de los parámetros positivistas, hubiera optado a su llegada al mundo científico por el materialismo histórico y dialectico ${ }^{12}$. En referencia a este panorama, Wallerstein señala que al institucionalizarse los intereses de la Geografía eran esencialmente los de una ciencia social, pero se resistía a la categorización: intentaba acercarse a las ciencias naturales gracias a su

12 En este punto radica la propuesta de renovación de la geografía que se lleva a cabo desde la década de los años setenta del siglo pasado, la cual como se verá en las próximas páginas y capítulos tiene como punto de ruptura las formulaciones del "método" marxistas en la trama de la "unidad" de la geografía. Cf. Moraes A y Wenderley Messias da Costa. (2009). Geografía crítica. La valorización del espacio. México: Ítaca. 
interés por la geografía física y las humanidades dentro de su preocupación por lo que se le llamaba geografía humana. A medida que, a fines del siglo XIX, el estudio de la realidad social se fue compartimentando cada vez más en disciplinas separadas, con una división clara del trabajo, la geografía empezó a parecer anacrónica en su tendencia generalista, sintetizadora y no analítica (Wallerstein, 2007, p. 29). Sin lugar a dudas el problema de fondo se sitúo en su origen dentro del positivismo clásico que la llevo a considerar por sus adeptos como una disciplina dual propia de su falsa unidad epistemológica :

con un dominio de geografía física ligado al campo de las ciencias naturales y un dominio de la geografía humana afín a las ciencias sociales, con relaciones mas divergentes que convergentes entre los dos subcampos. La geografía, considerada por los mismos geógrafos como un puente o una bisagra que articulaba las ciencias naturales y las humanas, al mismo tiempo que una ciencia síntesis, estableció, tanto con las ciencias naturales como con las sociales, una relación caracterizada por la importación de conceptos, métodos y resultados, sin lograr delimitar un campo propio de problemas de su especialidad. Refugiada en la docencia escolar y universitaria, la geografía fue considerada como un saber general y enciclopédico con poco o ningún carácter explicativo (Delgado, 2009, p. 92).

Debido a su fuerte orientación descriptiva, racional y pragmática, la Geografía tradicional se caracterizó desde su gestación por su enorme vacío teórico. La también conocida como ciencia "ingenua de lo concreto" o ciencia del "punto de vista", rechazó cualquier tipo de discusión teórica. En referencia a esto, para Yves Lacoste (1977, p. 62) los geógrafos han demostrado un total desprecio por las $<<$ consideraciones abstractas $>>$ y a menudo se han vanagloriado de un $<<$ espíritu a ras del suelo $>>$. En consonancia con los principios de la ciencia positiva definida por Comte, los ojos de los geógrafos eran educados para ver y estudiar los paisajes y sus significados, y no para buscar estructuras abstractas o posibles causalidades ocultas (Delgado, 2001), de manera que el método científico parece, finalmente, alcanzable para la Geografía: la descripción del inventariado, el trabajo de campo y la cartografía serán los recursos centrales de este dominio cientificista donde la observación en todos los casos es la fuente 
de conocimiento de estas prácticas ${ }^{13}$. En la coyuntura de la institucionalización de la Geografía, a decir de Perla Zusman (2014), la descripción fue definida como el método propio de este saber que lo diferenciaba de otros, parecería que el sentido común disciplinar la despojó del contenido procedimental para asociarla a la idea de inventario, al conocimiento enciclopédico, negándole todo potencial interpretativo o explicativo.

Respecto al trabajo de campo, calificado de forma clásica y también se podría decir de forma ocurrente como el sexto sentido del geógrafo, para los esquemas descriptivos y monográficos de la Geografía moderna constituye una parte esencial de estas metodologías, ya que le permiten al geógrafo aproximarse a las características que hacen del lugar un espacio único e irrepetible. Para entender mejor un espacio geográfico dentro de esta corriente de pensamiento es necesario una cercanía con el mismo, lo cual permite un conocimiento contextualizado y particular que no pretende llegar al nivel de las teorías (Lopez y Ramirez, 2015). Esto significa que para el método científico parece, finalmente, alcanzable por el trabajo de campo "que pasa a ser el laboratorio de los geógrafos" (Silveria, 2006a, p. 11[cursivas añadidas]). En el caso la cartografía dentro de este esquema positivista, formo parte de las tareas de localización, identificación y delimitación geográfica de los fenómenos observados y, por consiguiente, de situar acontecimientos, procesos y objetos dentro de un marco espacial fundamentalmente coherente. Su fundamento se encuentra en "la lógica cartesiana en la que se supone que la res extensa es muy distinta al ámbito de la mente y el pensamiento, y susceptible de una descripción plena dentro de un conjunto de coordenadas" (Harvey, 2007, p. 238).

13 Uno de los grandes males de la geografía es su arraigada vocación a la observación como fuente de conocimiento empírico. En referencia a esto algunos geógrafos justifican dicho procedimiento de la siguiente manera "Las fuentes más usuales del conocimiento geográfico suelen ser la observación, el levantamiento geográfico, el análisis espacial y la interpretación del espacio terrestre o espacio real. Aquí se entiende que la observación, según los actuales enfoques preferentes que utilizan los geógrafos, atañe al examen visual de los objetos, áreas y sistemas espaciales de la superficie terrestre y se busca esbozar un camino que haga emerger las propiedades de la observación como fuente del conocimiento geográfico. Para el caso se exploran varias formas de observación vinculadas a las nociones de 'espacio terrestre', que los geógrafos reducen a 'espacio geográfico' y algunos más avezados conciben como el ‘espacio organizado' y la 'organización espacial'. Respecto de las diversas acepciones para espacio terrestre, desde la perspectiva geográfica, la contribución deja en claro el papel del geógrafo como 'observador', la tierra habitada por los seres humanos como 'objeto de conocimiento', y, acertadamente, la observación como conexión lógica entre el observador y lo observado. (Gangas y Santis, 2001). 


\section{Conclusiones}

Como se sustenta, la Geografía moderna se fundamentó en generalizaciones ecléticas que planteaban cuestiones grandiosas sobre temas tales como el determinismo medioambiental, la relación social con la naturaleza, la influencia de la geografía en la historia, etcétera, en un ambiente académico cada vez más dominado por la experiencia profesional analítica. La geografía careció en sus orígenes de métodos para alcanzar una síntesis y superar los innumerables dualismos dentro de su materia. Las instituciones dominantes en la disciplina estaban más interesadas por las prácticas de descubrimiento y subordinación de la naturaleza y las técnicas de gestión del imperio que por la creación de una disciplina coherente. En consecuencia, la geografía académica planteaba grandes cuestiones pero con demasiada frecuencia trivializaba las respuestas (Harvey, 2007). De manera que la Geografía desde su origen guardo un malestar con la teoría, esto la rezagó respecto al desarrollo y consolidación del resto de disciplinas, no le permitió construir una base solida de reconocimiento público y limitó su participación profesional. La Geografía moderna será un reflejo fiel de lo que sostiene Hans Joas y Wolfgang Knöbl cuando señalan que

el intento que los positivistas hicieron de reducir a leyes a observaciones elementales, o de deducir leyes a partir de observaciones elementales y verificar esas leyes, esta, pues, condenado al fracaso. [...] (ya que las cuestiones teóricas abarcan) desde las generalizaciones empíricas hasta grandes sistemas interpretativos en los que están implicadas posiciones básicas frente al mundo de orden filosófico, metafísico, político y moral. Quien quiera pertenecer al mundo de las ciencias sociales, no podrá evitar en la discusión argumentativa en todos estos planos. La esperanza de poder limitarse a teorías puramente empíricas no puede cumplirse (2016, pp. 16-26).

Hoy en día no queda más que seguir con las tareas de reconstrucción histórica del desarrollo del pensamiento geográfico. Es sumamente necesario replantear y descubrir los hilos teóricos y epistemológicos que han dado vida a esta parcela del conocimiento, sobre todo ante la escasa, convencional y sesgada forma en que se conoce e investiga la trayectoria y curso de la Geografía. En este sentido, resulta pertinente comenzar a indagar nuevos campos de análisis, reflexión y discusión que permitan responder aquellas interrogantes que ayuden a seguir fortaleciendo un 
conocimiento científico tan importante para la sociedad como son los saberes y las prácticas geográficas.

\section{Referencias}

Bagú, S. (1980). Tiempo, realidad social y conocimiento. México: Siglo XXI, 1980.

Capel, H. (2016). Filosofía y ciencia en la Geografía, siglo XVI-XXI. En Investigaciones Geográficas, Boletín del Instituto de Geografía, 89, México, 5-22.

Capel, H. (2012). Filosofía y ciencia en la geografía contemporánea. Barcelona: Ediciones del Serbal.

De la Garza, E. y Gustavo Leyva. (2010). “Introducción”. En De la Garza, E. y Gustavo Leyva. Tratado de metodología de las ciencias sociales: perspectivas actuales. México: Fondo de Cultura Económica/ Universidad Autónoma Metropolitana (pp. 2-15).

Delgado, O. (2001). "Geografía, espacio y teoría social". En Sonia Aguirre, coord. Espacio Y Territorios: razón, pasión e imaginarios. Bogotá: Vicerrectoría General de la Universidad Nacional de Colombia.

Delgado, O. (2009). "Geografía y ciencia sociales. Un relación reexaminada”. En Martha Chávez, Octavio González y María del Carmen Ventura, edit. Geografía humana y ciencias sociales. Una relación reexaminada. México: El Colegio de Michoacán.

Engels, F. (2006). "Ludwig Feuerbach y el fin de la filosofía clásica alemana". En Engels, Friedrich y Karl Marx. Ludwig Feuerbach y el fin de la filosofía clásica alemana (y otros escritos sobre Feuerbach). Madrid: Fundación de Estudios Socialistas Federico Engels (pp. 7-55).

Engels, F y Karl Marx (2015). “ Manifiesto del partido comunista”. En Karl, Marx. Antología. Argentina, Siglo XXI. (pp. 110-150).

Gangas, M. y Hernán Santis (2001). "La observación como fuente del conocimiento geográfico". En Revista Geografía Norte Grande, 28.

Gilly, A. (2013). Historia a contrapelo. México: Era.

Harvey, D. (2007). Espacios del capital. Hacía una geografía crítica. Madrid: Akal.

Hobsbawm,E. (2009). La era de la revolución. 1789-1848. Buenos Aires: Crítica. 
Hobsbawm, E. (2012). La formación de la clase obrera en Inglaterra. Madrid: Capitan Swing.

Joas, H. y Wolfgang Knöbl (2016). Teoría social. Veinte lecciones introductorias. España: Akal.

Kosik, K. (1976). Dialéctica de lo concreto. México: Grijalbo.

Lacoste, Yves. (1977). La geografía un arma para la guerra. Barcelona: Anagrama.

León, E. (2016). "Geografía y ciencias sociales: dos proyectos en disputa". En Geografía crítica. Espacio, teoría social y geopolítica. México: Ítaca/Facultad de Filosofía y Letras de la Universidad Nacional Autónoma de México (pp. 17-34).

Lopez, L. y Ramírez, B. (2015). Espacio, paisaje, región, territorio y lugar: la diversidad en el pensamiento contemporáneo. México: Instituto de Geografía/UAM-Xochimilco.

Luxemburgo, R. (1967). La acumulación del capital. México: Grijalbo.

Marini, R. (1994). La sociología latinoamericana. Origen y perspectiva. Consultado en <http://www.marini-escritos.unam.mx/083_sociologia_latinoamericana.html $>$.

Marini, R. (1983). "Razón y sinrazón de la sociología marxista". Teoría marxista de las clases sociales. Cuadernos de Teoría social. México: División de ciencias sociales y humanidades de la Universidad Autónoma Metropolitana Unidad Iztapalapa. Consultado <http://www. marini-escritos.unam.mx/062_sociologia_marxista.html $>$.

Marx, K. (2008). "La llamada acumulación originaria". El capital, libro 1, vol. 3, cap. XXIV. México: Siglo XXI, 2008.

Moraes, A. y Messias da Costa, W. (2009). Geografía crítica. La valorización del espacio. México: Ítaca.

Moraes, A. (2006). Geografía. Pequeña historia crítica, Buenos Aires: GEOUNTREF-EDUNTREF.

Moraes, A. (1987). A gēnese da geografía moderna. Sao Paulo: HUCITEC/Universidade de Sāo Paulo.

Moreira, Ruy (2017). Qué es la geografía. La Paz: Vicepresidencia del Estado Plurinacional de Bolivia/Centro de Investigaciones Sociales. Morín, E. (2010). A favor y en contra de Marx. Argentina: Nueva visión. Morín, E. (1999). Los 7 saberes necesarios para la educación del futuro. Francia: Santillana/UNESC0. 
Ortega, J. (2000). Los horizontes de la geografía. Barcelona: Ariel.

Osorio, J. (2016). Fundamentos del análisis social. México: Fondo de cultura económica.

Osorio, J. (2017). Sistema mundial, intercambio desigual y renta de la tierra. Ciudad de México: División de Ciencias Sociales y Humanidades de la Universidad Autónoma Metropolitana Unidad Xochimilco/ Itaca.

Peet, R. (2012). "Los orígenes sociales del determinismo ambiental”. En Benach, Nuria. Richard Peet. Geografía contra el neoliberalismo. Barcelona: Icaria. (pp. 95-180).

Porto Gonçalves, C. (2001). Geo-grafías. México: Siglo XXI.

Poulantzas, N. (1976). Poder político y clases sociales en el estado capitalista. México: Siglo XXI.

Reynaud, A. (1976). El mito de la geografía. En Geocrítica. Cuadernos Críticos de Geografía Humana, 2. Consultado en http://www.ub.edu/ geocrit/geo2.htm

Santos, M. (1990). Por una geografía nueva. España: Espasa/Calpe.

Silveira, M. (2006a). Indagaciones y senderos de la geografía. En: Cuadernos de Geografía, 15, 7-19.

Silveira, M. (2006b). Espejismos y horizontes de la geografía contemporánea. En Párrafos geográficos, 5, (1), 54-73.

Unwin, T. (1995). El lugar de la geografía. Madrid: Cátedra.

Uribe, G. (1998). Geografía y Sociedad. Exploraciones en compromisos y propuestas actuales. México: Centro de Investigación Científica "Ing. Jorge L. Tamyo".

Wallerstein, I. (2007). Abrir las ciencias sociales. México: Siglo XXI/Centro de Investigación Interdisciplinarias en Ciencias y Humanidades de la Universidad Nacional Autónoma de México.

Zusman, P. (2014). "La descripción en geografía. Un método, una trama". En: Boletín de estudios geográficos, 102, 135-149. 